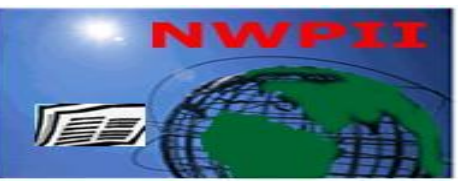

American Journal of Biomedical Sciences

ISSN: 1937-9080

nwpii.com/ajbms

\title{
Physiological Positive Feedback Mechanisms
}

\author{
Khaled A. Abdel-Sater* \\ Department of Physiology, Faculty of Medicine, Al-Azhar University- Assiut Branch, Egypt \\ Department of Physiology, Faculty of Medicine, King Abdul Aziz University- Rabigh Branch, Saudi Arabia \\ *Corresponding Author \\ Khaled Ahmed Abdel-Sater Eliwa \\ Department of Physiology \\ Faculty of Medicine \\ Al-Azhar University- Egypt \\ King Abdul Aziz University- KSA \\ Mobile: In Egypt +20167970804 \\ In KSA +966-502470699 \\ E-mail: Khaled_71111@yahoo.com \& keliwa@kau.edu.sa \\ Website: http://www.kau.edu.sa/DRS-0056982.aspx
}

Received: 16 December 2010; $\mid$ Revised: 18 January 2011; $\mid$ Accepted: 13 March 2011

\begin{abstract}
In positive feedback mechanisms, the response to a stimulus does not stop or reverse it but instead keeps the sequence of events going up. At first glance, this would appear to be a counter to the principle of homeostasis, since a positive feedback loop has no obvious means of stopping. Not surprisingly, therefore, the positive feedback is less common in nature than the negative one. A positive feedback mechanism can be harmful, as in case of fever that causes metabolic changes pushing it to be higher. However, in some instances, the body uses this mechanism for its advantage. A good example of significant positive feedback is the childbirth. Ovulation, coagulation, platelet aggregation, inflammation and shock are other instances in which the positive feedback plays a valuable role.
\end{abstract}

Keywords: Physiology, Homeostasis, Positive feedback mechanisms.

\section{Introduction}

There are two types of feedback mechanisms; negative feedback - the effector reverses the deviation from set point and positive feedback the action of the effector amplifies the change. In negative feedback loops, when the brain receives information about a change or deviation in the body's internal conditions, it sends out signals Am. J. Biomed. Sci. 2011, 3(2), 145-155; doi: 10.5099/aj110200145 along nerves. These signals prompt the changes in function that correct the deviation and bring the internal conditions back to the normal range [1].

An example of a negative feedback loop is the regulation of blood pressure. Any increase in the blood pressure is detected by receptors in the blood vessels that sense the resistance of blood flow against the vessel walls. These receptors relay a message to the brain, which in turn sends a message to the effectors, the heart and blood (C) 2011 by NWPII. All rights reserved. 
vessels. The heart rate decreases and blood vessels increase in diameter, which cause the blood pressure to fall back within the normal range. Conversely, if blood pressure decreases, the receptors relay a message to the brain, which in turn causes the heart rate to increase, and the blood vessels to decrease in diameter [2].

In some cases, the metabolic parameter regulated by a hormone (e.g., plasma glucose concentration) rather than the hormone itself represents the feedback signal. For example, glucagon increases blood glucose level (while insulin decreases it), which in turn inhibits the secretion of glucagon (and stimulates that of insulin). Neuronal signals can also serve as feedback (neuroendocrine feedback) used, for example, to regulate plasma osmolality [3].

Positive feedback mechanisms are designed to accelerate or enhance ongoing output that has been activated by a stimulus. Unlike negative feedback mechanisms that are initiated to maintain or regulate conditions within a set and narrow range, positive feedback mechanisms 'push' levels beyond normal ranges. Clearly, if unchecked, positive feedback can lead to a vicious cycle and dangerous situations. Thus, positive feedback mechanisms require an external brake to terminate them [4]. Sometimes, it is the physician's task to interrupt such a positive-feedback loop [5]. Several examples of positive feedback mechanisms will be given.

\section{Positive Feedback Effect of Estrogen before Ovulation-the Preovulatory LH Surge}

GnRH (gonadotropin releasing hormone) stimulates the secretion of the pituitary gonadotropins; LH (luteinizing hormone) and FSH (follicle stimulating hormone). During the female reproductive cycle, ovarian estradiol exerts negative feedback to reduce gonadotropin release [6]. However, in the late follicular phase (2 days before ovulation), and in response to sustained high levels of estradiol from preovulatory follicles, the action of estradiol switches from negative to positive feedback, resulting in a surge release of $\mathrm{GnRH}$, that is likely due to increased GnRH neuron firing activity. Estradiol sensitizes the pituitary to GnRH and enhances the self- priming action of GnRH on the pituitary gonadotrophs [5]. The GnRH surge triggers a surge of LH secretion. The secreted LH then acts on the ovaries to stimulate an additional secretion of estrogen, which in turn causes more secretion of LH to initiate ovulation [7]. Ovulation occurs about 9 hours after the LH peak. Eventually, LH reaches an appropriate concentration, and typical negative feedback control of hormone secretion is then exerted [8].

There is an evidence that in primates, both negative and positive feedback effects of estrogen are exerted in the mediobasal hypothalamus, but exactly how negative feedback is switched to positive feedback and then back to negative feedback in the luteal phase remains unknown [8];[9]. However, there is a factor explaining this mechanism which is the increase in the number of $\mathrm{GnRH}$ receptors on the gonadotrophs, increasing pituitary responsiveness to $\mathrm{GnRH}$. Another factor is the conversion of the storage pool of $\mathrm{LH}$ (perhaps within a subpopulation of gonadotrophs) to a readily releasable pool [5]. Estradiol must be maintained at a critical concentration (about 300 $\mathrm{pg} / \mathrm{mL}$ ) for a sufficient duration (36 to 48 hours) prior to its surge. Any reduction of the estradiol rise or a rise that is too small or too short eliminates or reduces the LH surge. Moreover, high concentrations of estradiol in the presence of elevated progesterone do not induce an LH surge [5]. The extent to which other ovarian hormones, such as progesterone, participate in the positive feedback mechanism at midcycle is less clear. At midcycle, the shift in steroidogenesis represents the ability of the preovulatory follicle to produce more progesterone than estradiol [10]. It is possible, that at midcycle the role of progesterone is permissive [11]. Additional information in ovariectomized and adrenalectomized rats indicates that neuroprogesterone synthesized in the hypothalamus under the influence of estradiol is an obligatory mediator of the positive feedback mechanism that is induced by this steroid [12]. Furthermore, data in rats have shown that estrogens induce de novo synthesis of progesterone from cholesterol in the hypothalamus, which plays a role in the onset of the LH surge [13]. Therefore, it is proposed that progest-estrogenic mechanisms involving the

(C) 2011 by NWPII. All rights reserved. 
progesterone receptors participate in the estradiol positive feedback mechanism, and thus regulating the LH surge onset [12]. Ovarian factors rather than exhaustion of pituitary reserves are suggested to be important for termination of the endogenous LH surge during the normal menstrual cycle [14].

\section{Onset of Labor-A Positive Feedback Mechanism for Its Initiation}

Early in gestation, during the first two trimesters, the uterus remains relatively inactive because of the inhibitory effect of the high levels of progesterone on the uterine wall. However, during the last trimester, the uterus becomes increasingly more excitable, resulting in mild contractions called Braxton Hicks contractions occurring with increasing strength and frequency [15]. Another change that occurs is the ripening of the cervix. During gestation, the exit of the uterus remains sealed or closed by the tightly closed cervix. As labor approaches however, the cervix begins to soften. This process of softening is known as "ripening". This results in the cervix to become malleable so that it can gradually yield and dilate as the fetus is forcefully pushed against it during labor [16].

Each uterine contraction begins at the top of the uterus and sweeps downwards, forcing the fetus toward the cervix. The pressure of the fetus against the ripened cervix opens the cervical canal. As labor begins, the cervix of the uterus is stretched, which generates sensory impulses to the hypothalamus, which in turn stimulates the posterior pituitary to release oxytocin. Oxytocin produces more powerful uterine contractions so that the fetus is pushed more forcefully against the cervix, stimulating more oxytocin release in a continuous positive feedback cycle [17]. This is reinforced as oxytocin stimulates prostaglandin production by the uterine lining, further enhancing uterine contractions [18]. It has been discovered that the placenta itself secretes oxytocin at the end of gestation and in an amount far higher than that from the posterior pituitary gland [19]. The external brake or shutoff of the feedback cycle is delivery of the baby and the placenta [9]. Circulating oxytocin does not increase in late pregnancy and even in labor until after full cervical dilatation. However, the concentration of uterine oxytocin receptors increases more than 100-fold toward the end of pregnancy [20]. The rising secretion of estrogens (primarily estriol), formed from fetoplacental unit, stimulates the uterus to (1) produce receptors for oxytocin; (2) produce receptors for prostaglandins; and (3) produce gap junctions between myometrial cells in the uterus [21].

Oxytocin induces uterine contractions in two ways. Oxytocin stimulates the release of prostaglandin E2 and prostaglandin F2a in fetal membranes by activation of phospholipase $\mathrm{C}$. The prostaglandins stimulate uterine contractility [9]. Oxytocin can also directly induce myometrial contractions through phospholipase $\mathrm{C}$, which in turn activates calcium channels and the release of calcium from intracellular stores [22].

Oxytocin also protects against hemorrhage after expulsion of the placenta. Just prior to delivery, the uterus receives nearly $25 \%$ of the cardiac output, most of which flows through the low resistance pathways of the maternal portion of the placenta [20].

After labor, release of milk at the nipple stimulates the baby to start suckling vigorously, which stimulates the receptors in the nipple even more, so that there is even more oxytocin released from the maternal pituitary and even more milk is released and so on, until the baby is satiated and unlatches from the breast, when everything goes back to normal. This is a positive feedback mechanism [23].

\section{Positive Feedbacks of Coagulation Cascade}

The cascade is a multi-component enzyme system of circulating inactive proenzymes, forming a sequential self-amplification process [24].

Because the amount of thrombin generated at this stage is still too small to activate fibrinogen to fibrin, there are several positive feedback amplification mechanisms. There are four significant feedback loops of coagulation and all are catalyzed by $\mathrm{FXa}$ ( $\mathrm{F}$ indicates factor, a indicates active) or thrombin [25].

The activation of TF: VII complex $(\mathrm{TF}=$ tissue factor) by $\mathrm{FXa}$ is the major initiating feedback 
loop of clotting. When TF is available to the plasma, the former binds with a very high affinity to FVII or FVIIa. Most of the available TF surely binds to the inactive zymogen FVII, thereby forming the TF:FVII complex [26].

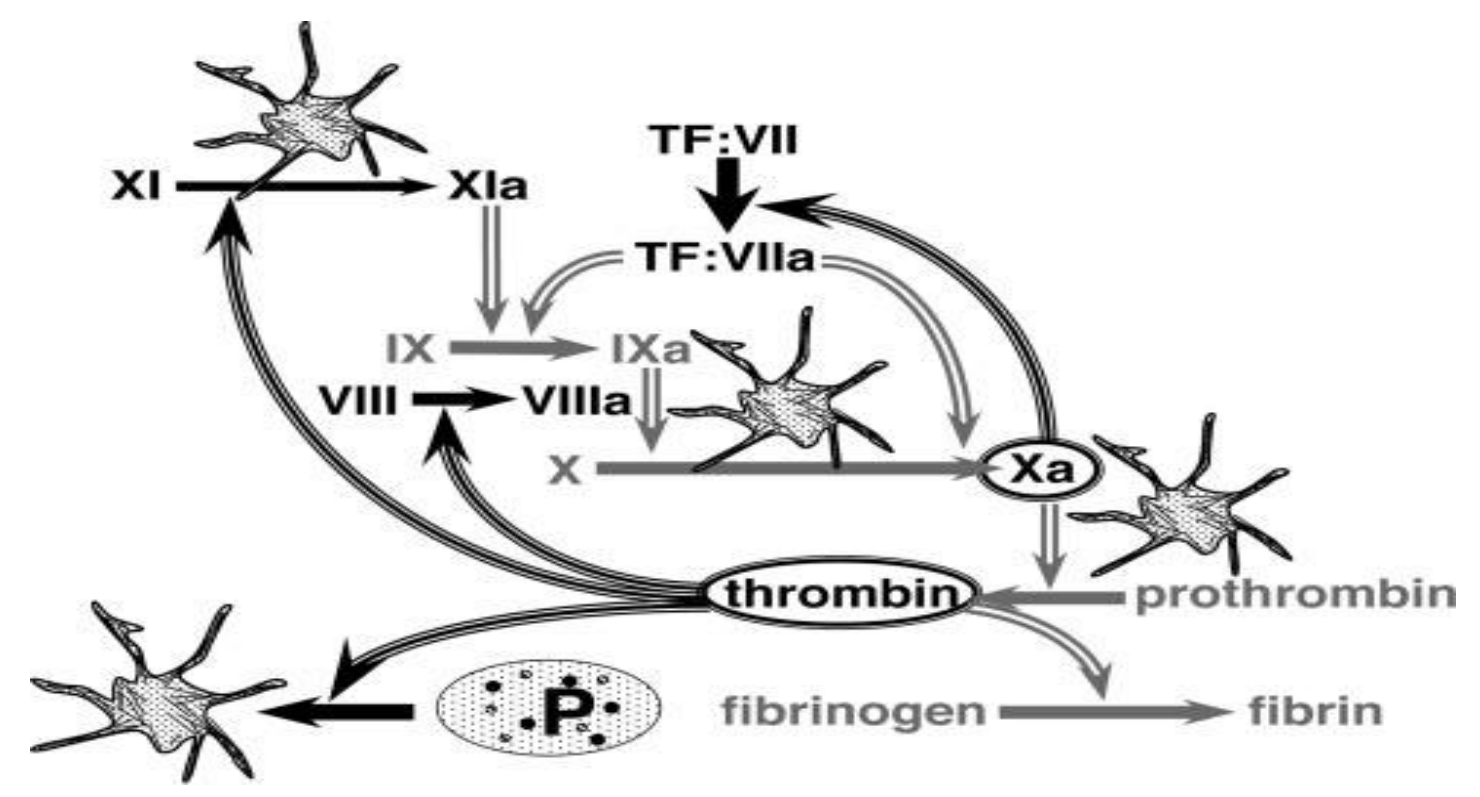

Figure 1: The major positive feedback loops of coagulation. Four significant feedback loops are highlighted by bold triple arrows. $\mathrm{P}$ indicates platelet and

The activation of FVIII by thrombin is another important step. Although FXa is capable of activating FVIII [27]. Factor VIII circulates bound to von Willebrand factor, which is an adhesive protein important for the generation of the initial platelet plug [28]. After activation, factor VIIIa dissociates from von Willebrand factor and forms a complex on the platelet surface with factor IXa; this complex then activates factor $\mathrm{X}$ [29].

Activation of factor XI by thrombin in the presence of activated platelets is another amplification positive feedback loop, resulting in the generation of additional factor IXa, which in turn activates factor $\mathrm{X}$ [25].

Thrombin is a major activator of platelets. The activated platelets are required for numerous reactions of the central core of the clotting pathways. Activation of platelets is associated with the exposure of negatively charged phospholipids, which have high potential to bind coagulation factors and assemble enzyme-cofactor complexes that are crucially important for efficient propagation of the system [29].

Excess thrombin would exert a positive feedback effect on the clotting cascade, and results in splitting of more prothrombin to thrombin, more clotting, more thrombin formed, and so on [30]. Fibrinolysis and antithrombin help to prevent this, as does the fibrin of the clot, which adsorbs excess thrombin and renders it inactive. All of these factors are the external brake for this positive feedback mechanism. Together they usually limit the fibrin formed to what is needed to create a useful clot but not an obstructive one [6].

\section{Positive Feedback of Platelet Aggregation}

In normal haemostasis, platelets adhere to collagen or sub-endothelial microfibrils via an intermediary called von Willebrand factor (vWF), a plasma protein secreted by endothelial cells and platelets. The vWF forms a bridge between the damaged vessel wall and the platelets. The platelets then undergo a marked shape change and 
release various chemicals including adenosine diphosphate (ADP), serotonin and fibrinogen, which cause platelet aggregation [31].

Thrombin and other ligands activate their respective receptors and cause inositol trisphosphate mediated release of $\mathrm{Ca}^{++}$from the dense tubular system. Receptor activation also produces diacylglycerol (DAG) [32]. Elevated $\mathrm{Ca}^{++}$activates phospholipase $\mathrm{A}_{2}$, an enzyme that cleaves arachidonic acid from DAG. Platelets are rich in cyclo-oxygenase 1 and, therefore, metabolize the arachidonic acid to prostaglandins, including PGG2 (endoperoxide) and PGH2. Platelets also contain thromboxane synthetase, which converts $\mathrm{PGH} 2$ to thromboxane A2. Thromboxane A2 diffuses out of the platelet, activates membrane receptors, and establishes a positive feedback mechanism for the production of more prostaglandins [33].

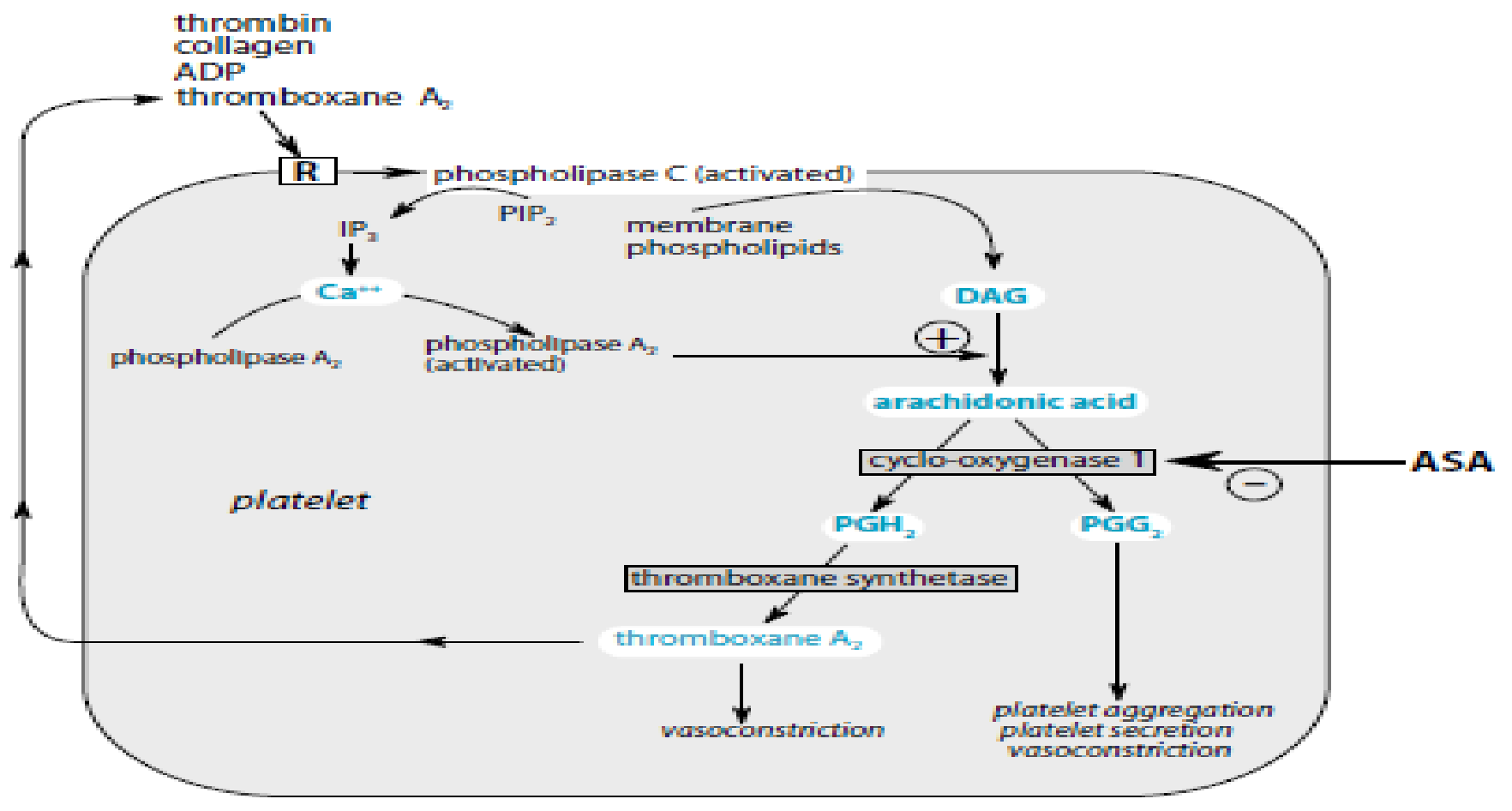

Figure 2: Mechanism of Positive feedback of platelet aggregation. (IP3) is inositol trisphosphate, (PGG2) is endoperoxide and (DAG) indicates diacylglycerol and (ASA) indicates acetyl salicylic acid (aspirin) [32].

The vessel walls also possess prostaglandin synthesizing enzymes but here the main product of cyclic endoperoxide is $\mathrm{PGI}_{2}$; the cyclic endoperoxide generated by adhered platelets can also be metabolized in the vessel wall to $\mathrm{PGI}_{2}$ [34]. $\mathrm{PGI}_{2}$, in contrast to thromboxane $\mathrm{A}_{2}$, is a vasodilator and inhibitor of platelet function since it potentiates the action of adenyl cyclase and so increases platelet cyclic AMP levels. The balance between the generation of thromboxane $A_{2}$ and $\mathrm{PGI}_{2}$ is obviously vitally important for the regulation of platelet function [35].

Peroxides and thromboxane $\mathrm{A}_{2}$ cause new platelets to adhere to the old ones, a positive feedback phenomenon termed platelet aggregation, which rapidly creates a platelet plug inside the vessel [36].

The platelet-plugging mechanism is extremely important for closing minute ruptures in very small blood vessels that occur many thousands of times daily. Indeed, multiple small holes through the endothelial cells themselves are often closed by platelets actually fusing with the endothelial cells to form additional endothelial cell membrane [8]. Aspirin inhibits the cyclooxygenase enzyme and thereby inhibits the release reaction and consequent formation of a platelet plug [21]. 


\section{Positive Feedback Mechanisms in Irreversible Shock}

Circulatory shock is defined as an inadequate blood flow throughout the body. It is a clinical condition characterized by a gradual fall in arterial blood pressure and rapid heart rate. Respiration is also rapid and the skin is moist, pale or bluishgrey [37].

The body responds to hypotension by activating neurohumoral mechanisms that serve as negative feedback - compensatory mechanisms to restore arterial pressure. Without medical intervention, progressive shock becomes irreversible. The irreversible shock leads to death.
Death occurs as a result of development of multiple positive feedback cycles (death cycles) [38]. During progressive shock, the blood pressure declines to a very low level that is not adequate to maintain blood flow to the cardiac muscle; thus the heart begins to deteriorate. Prolonged hypotension with accompanying tissue hypoxia results in metabolic acidosis as organs begin to generate ATP by anaerobic pathways [39]. Acidosis impairs cardiac contraction and vascular smooth muscle contraction, which decreases cardiac output and systemic vascular resistance, thereby lowering the arterial pressure even more [40].

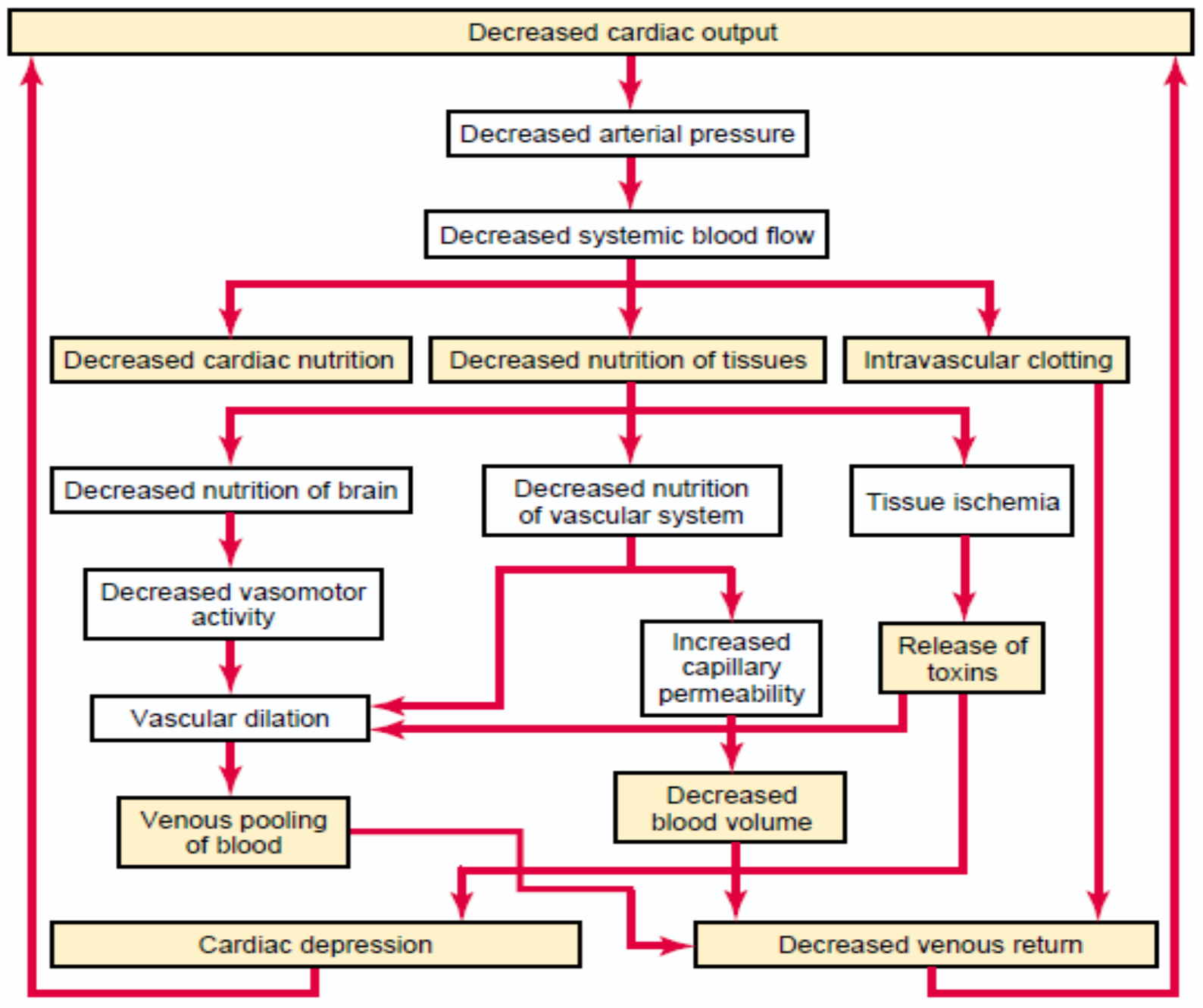

Figure 3: Different types of "positive feedback" that can lead to progression of shock [8]. 
When the blood pressure declines to a very low level, blood begins to clot in the small vessels. Eventually blood vessel dilation begins as a result of decreased sympathetic activity and because of the lack of oxygen in capillary beds [41]. Capillary permeability increases under ischemic conditions, allowing fluid to leave the blood vessels and enter the interstitial spaces, and finally intense tissue deterioration begins in response to inadequate blood flow. Also vasodilatation leads to more hypotension and so on till death occurs [39]. Irreversible shock leads to death, regardless of the amount or type of medical treatment applied. In this stage of shock, the damage of tissues, including cells, cardiac muscle and vasoconstrictor center is so extensive. The patient is destined to die even if the adequate blood volume is reestablished and blood pressure is elevated to its normal value [37].

\section{Positive Feedback Mechanisms in Inflammation}

Inflammation is characterized by increased blood flow to the tissue causing increased temperature, redness, swelling, and pain. Inflammation is a beneficial process up to a point. Increased blood flow accelerates delivery of the white blood cells that combat invading foreign substances or organisms and clean up the debris of injured and dead cells. In addition, increased blood flow provides more oxygen and nutrients to cells at the site of damage and facilitates removal of toxins and wastes [42]. Increased permeability of the microvasculature allows fluid to accumulate in the extravascular space in the vicinity of the injury and thus dilute noxious agents [20].

It may, however, become a vicious cycle of damage, inflammation, more damage, more inflammation, and so on-a positive feedback mechanism [30]. Lysosomal hydrolases released during phagocytosis of cellular debris or invading organisms may damage the nearby cells that were not harmed by the initial insult. Loss of fluid from the microvasculature at the site of injury may increase viscosity of the blood, slowing its flow, and even leaving some capillaries clogged with stagnant red blood cells. Decreased perfusion may cause further cell damage [20]. In addition, massive disseminated fluid loss into the extravascular space sometimes compromises cardiovascular function [43].

Activated neutrophils release prostaglandins which cause microvascular leakage, possibly by stimulating mast cells to release histamine; prostaglandins also attract leukocytes. Neutrophils and macrophages release proteases when stimulated, which cause microvascular leakage, attract more neutrophils and eosinophils, and degrade basement membranes. It is another positive feedback mechanism [44].

Normal cortisol secretion seems to be the brake, to limit the inflammation process to what is useful for tissue repair, and to prevent excessive tissue destruction. Cortisol blocks the effects of histamine and stabilizes lysosomal membranes, preventing excessive tissue destruction [45]. Too much cortisol, however, decreases the immune response, leaving the body susceptible to infection and significantly slowing the healing of damaged tissue [46].

\section{Positive Feedback of the Fevers}

The body temperature remains within normal range through a balance between heat gain and heat loss. The thermostat has a normal set-point at $37^{\circ}$ C. Deviation of hypothalamic temperature away from this point activates appropriate responses in the opposite direction to return the body temperature to the normal level. Within the comfortable zone of external temperature the heat gain is equal to heat loss without the use of any heat regulating mechanism [47].

Fever may be provoked by many stimuli. Most often, they are bacteria and their endotoxins, viruses, yeasts, spirochets, protozoa, immune reactions, several hormones, medications and synthetic polynucleotides. These substances are commonly called exogenic pyrogens [48].

Cells stimulated by exogenic pyrogens form and produce cytokines called endogenic pyrogens. The most important endogenic pyrogens are interleukins (especially IL-1 $\beta$ and IL-6) and the tumour necrosis factor- $\alpha$ (TNF- $\alpha$ ). They are produced not only by monocytes and macrophages but also by endothelial cells and astrocytes [48]. Released IL-1 $\beta$, IL-6 and TNF- $\alpha$ are transported

(C) 2011 by NWPII. All rights reserved. 
by blood. These cytokines bind to their own specific receptors located in close proximity to the preoptic region of the anterior hypothalamus [49]. Here, the cytokine receptor interaction activates phospholipase $\mathrm{A}_{2}$, resulting in the liberation of plasma membrane arachidonic acid (by cyclooxygenase) which is subsequently converted to prostaglandin $\mathrm{E}_{2}\left(\mathrm{PGE}_{2}\right)$ [50]. $\mathrm{PGE}_{2}$ diffuses across the blood brain barrier, where it causes the set-point of the hypothalamic thermostat to rise [51]. Within a few hours after the set-point has been increased, the body temperature also approaches this level [49].

Aspirin and the non-steroidal antiinflammatory drugs display antipyretic activity by inhibiting the cyclo-oxygenase, an enzyme responsible for the synthesis of $\mathrm{PGE}_{2}$ [52]. Glucocorticoids exert their antipyretic effect at two levels; at the level of the macrophage by inhibiting cytokines production and at the level of the hypothalamus by interfering with prostaglandin synthesis [53].

However, there are indications that the development of fever is of benefit as a normal body defense in combating some infections. Temperature elevation has been shown to enhance several parameters of immune function, including antibody production, T-cell activation, production of cytokines, and enhanced neutrophil and macrophage function [52]. Furthermore, some pathogens such as Streptococcus pneumoniae are inhibited by febrile temperatures [49].

Fever increases the chemical reactions of the body by an average of about 12 per cent for every $1{ }^{\circ} \mathrm{C}$ rise in temperature. It increases the metabolic rate, which increases heat production, which in turn raises body temperature even more. This is a positive feedback mechanism that will continue until an external event (such as antipyretic or death of the pathogens) acts as a brake [50]. Death occurs at a body temperature of $45^{\circ} \mathrm{C}$ because cellular proteins denature at this temperature and metabolism stops [54].

\section{Conclusion}

Positive feedback is a control system that requires an external interruption or brake [9]. These mechanisms have the potential to become self-perpetuating and harmful; however, in some instances, the body uses positive feedback to advantage as I have described. Certainly, other examples exist. The renal counter-current exchange multiplier employs positive feedback to multiply the concentration of interstitial fluid and fluid in the descending limb [21]. In neural circuits, a positive feedback loop may be activated that leads to continued reverberation that, in essence, stimulates itself until synaptic fatigue or inhibitory stimuli break the cycle [55]. In cardiac muscle, increased calcium influx into the cytosol increases calcium release from the sarcoplasmic reticulum by a positive feedback mechanism [56]. Subsequently, $\mathrm{Ca}^{2+}$ binds to troponin $\mathrm{C}$ and starts the cross-bridge movement of the myofibrils resulting in force development and contraction [6]. Micturition [5], cortisol and dehydroepiandrosterone production in late pregnancy [57], cochlear mechanics [58], membrane depolarization [6], and apoptosis [59] are other examples. Though less familiar and undoubtedly less intuitive than negative feedback mechanisms, positive feedback mechanisms serve a valuable function.

\section{References}

1-Taniguchi, F.; Couse, J.; Rodriguez, K.; Emmen, J.; Poirier, D.; Korach, K. Estrogen receptor- $\alpha$ mediates an intraovarian negative feedback loop on thecal cell steroidogenesis via modulation of CYP17A1 (cytochrome P450, steroid 17 $\alpha$-hydroxylase/17,20 lyase) expression. FASEB J, 2007, 21(2), 586-595. DOI: 10. 1096/ fj.06-6681com.

2-Kubota, Y.; Suda, T. Feedback mechanism between blood vessels and astrocytes in retinal vascular development. Trends Cardiovasc Med, 2009, 19(2), 38-43. DOI:10.1016/ j.tcm.2009.04.004.

3-Despopoulos, A.; Silbernagl, S. Color Atlas of Physiology, Thieme Stuttgart. New York, $5^{\text {th }}$ ed., 2003. PP 4-5. ISBN: 1-58890-061-4 (TNY).

4-Niell, C. Theoretical analysis of a synaptotropic dendrite growth mechanism. Journal of Theoretical Biology, 2006, 241(1-7), 39-48. DOI:10.1016/j.jtbi.2005.11.014.

(C) 2011 by NWPII. All rights reserved. 
5-Rodney, R.; Tanner, G. Medical Physiology, Lippincott Williams \& Wilkins, $2^{\text {nd }}$ ed., 2003. PP 667 -678. ISBN: 0781719364.

6-Banerjee, A. Clinical Physiology, An Examination Primer, Cambridge University Press, Cambridge, New York, Melbourne, Madrid, Cape Town, Singapore, São Paulo, $1^{\text {st }}$ ed., 2005; PP 162-166. ISBN:13:978-0-511-129278.

7-Kerdelhue, B.; Brown, S.; Lenoir, V.; Queenan, J.; Jones, G.; Scholler, R.; Jones, H. Timing of initiation of the preovulatory luteinizing hormone surge and its relationship with the circadian cortisol rhythm in the human. Neuroendocrinology, 2002, 75, 158-163. DOI:10.1159/000048233.

8-Guyton, A.; Hall, J. Textbook of medical physiology; Elsevier academic press. Philadelphia, Pennsylvania, 11th ed., 2006. PP 458 \& 909. ISBN: 0-8089-2317-X.

9-Ganong, W. Review of Medical Physiology, Chapter 25. The Gonads: Development \& function of the reproductive system. McGrawHill Medical, $22^{\text {nd }}$ ed., 2005. ISBN: 978-0-07160567-0.

10-Mcnatty K.; Smith, D.; Makris, A.; Osathanondh, R.; Ryan, K. The microenvironment of the human antral follicle: Interrelationships among the steroid levels in antral fluid, the population of granulosa cells, and the status of the oocyte in vivo and in vitro. J Clin Endocrinol Metab, 1979, 49, 851860. PMID: 511976.

11-Messinis, I.; Templeton, A. Effects of supraphysiological concentrations of progesterone on the characteristics of the oestradiol-induced gonadotrophin surge in women. J Reprod Fertil, 1990, 88, 513-519. DOI: 10.1530/jrf.0.0880513.

12-Micevych, P.; Sinchak, K.; Mills, R.; Tao, L.; Lapolt, P.; Lu, J. The luteinizing hormone surge is preceded by an estrogen-induced increase of hypothalamic progesterone in ovariectomized and adrenalectomized rats. Neuroendocrinology, 2003, 78, 29-35. DOI: 10.1159/000071703.

13-Soma, K.; Sinchak, K.; Lakhter, A.; Schlinger, B.; Micevych, P. Neurosteroids and female reproduction: Estrogen increases 3beta-HSD
mRNA and activity in rat hypothalamus. Endocrinology, 2005, 146, 4386-4390. DOI:10.1210/en.2005-0569.

14-Dafopoulos, K.; Mademtzis, I.; Vanakara, P.; Kallitsaris, A.; Stamatiou, G.; Kotsovassilis, C.; Messinis, I. Evidence that termination of the estradiol-induced luteinizing hormone surge in women is regulated by ovarian factors. J Clini Endocrinol and Metabol, 2006, 91(2), 641-645. DOI: 10.1210/jc.20051656.

15-Weiss, G. Endocrinology of Parturition. The Journal of Clinical Endocrinology and Metabolism, 2000, 85 (12), 4421-4425. DOI: 10.1210/jc.85.12.4421.

16-Gimpl, G.; Fahrenholz, F. The Oxytocin receptor system: Structure, function, and regulation. Physiological Reviews, 2001, 81(2), 629-683. PMID: 11274341.

17-Chibbar, R.; Miller, F.; Mitchell, F. Synthesis of oxytocin in amnion, chorion and decidua may influence the timing of human parturition. J Clin Invest, 1993, 91, 185-192. DOI: 10.1172/JCI116169.

18-Sugimoto, Y.; Yamasaki, A.; Segi, E.; Tsuboi, K.; Aze, Y.; Nishimura, T.; Oida, H.; Yoshida, N.; Tanaka, T.; Katsuyama, M.; Hasumoto, K.; Murata, T.; Hirata, M.; Ushikubi, F.; Negishi, M.; Ichikawa, A.; Narumiya, S. Failure of parturition in mice lacking the prostaglandin $\mathrm{F}$ receptor. Science, 1997, 277, 681-683. DOI:10.1126/science. 277.5326.681.

19-Norwitz, E.; Robinson, J.; Challis, J. The control of labor. N Engl J Med, 1999, 341, 660 666.

20-Johnson, L. Essential Medical Physiology; Elsevier academic press -Amsterdam Boston Heidelberg London New York Oxford Paris San Diego San Francisco Singapore Sydney Tokyo, ${ }^{\text {rd }}$ ed., 2003. PP 481-485. ISBN: 012-387584-6.

21-Fox, S. Human Physiology; McGraw-Hill Companies, $9^{\text {th }}$ ed., 2006. PP 674-677. ISBN: 0072908017.

22-Rivera, J.; Lopez, B.; Varney, M.; Watson, S. Inositol 1, 4, 5-triphosphate and oxytocin binding in human myometrium. 
Endocrinology, 1990, 127, 155-162. PMID: 2163308.

23-Bartels, A.; Zeki, S. The neural correlates of maternal and romantic love. Neuroimage, 2004, 21, 1155-1166. DOI: 10.1016/j.neuroimage.2003.11.003.

24-Bombeli, L.; Spahn, D. Updates in perioperative coagulation: physiology and management of thromboembolism and hemorrhage. British Journal of Anaesthesia, 2004, 93 (2), 275-87. DOI:10. 1093/ bja/ aeh174.

25-Jesty, J.; Beltrami, E. Positive Feedbacks of Coagulation: Their Role in Threshold Regulation. Arterioscler Thromb Vasc Biol, 2005, 25, 2463-2469. DOI: 10. 1161/ 01. ATV. 0000187463.91403.b2.

26-Morrissey, J.; Macik, B.; Neuenschwander, P.; Comp, P. Quantitation of activated factor VII levels in plasma using a tissue factor mutant selectively deficient in promoting factor VII activation. Blood, 81, 734-744, 1993. PMID: 8427965.

27-Mertens, J.; Bertina, R. Activation of human coagulation factor VIII by activated factor X, the common product of the intrinsic and the extrinsic pathway of blood coagulation. Thromb Haemost, 1982, 47 (2), 96 -100. PMID 6808697.

28-Sadler, J. Biochemistry and genetics of von Willebrand factor. Annu Rev Biochem, 1998, 67, 395-424.

DOI:

10.1146/annurev.biochem. 67.1.395.

29-Baglia, F.; Walsh, P. Thrombin-mediated feedback activation of factor XI on the activated platelet surface is preferred over contact activation by factor XIIa or factor XIa. J Biol Chem, 2000, 275, 20514-20519. DOI: 10.1074/jbc.M000464200.

30-Scanlon, V.; Sanders, T. Essentials of Anatomy and Physiology; F. A. Davis Company, Philadelphia, $5^{\text {th }}$ ed., 2007. PP 263-268. ISBN: 13: 978-0-8036-1546-5.

31-Diana, S.; Chanarin, I.; Reid C. Recent advances in haematology. Postgraduate Medical Journal,1981, 57, 139-149. DOI: 10.1136/pgmj.57.665.139.
32-Ackermann, U. $P D Q$ Physiology ( $P D Q$ Series), BC Decker Inc. (Hamilton), $1^{\text {st }}$ ed., 2002. PP 93-96. ISBN: 1-55009-148-4.

33-Michelson, A.; Barnard, M.; Khuri, S.; Rohrer, M.; Mac-Gregor, H.; Valeri, C. The effects of aspirin and hypothermia on platelet function in vivo. Br J Haematol, 1999, 104, 64-68. DOI: 10.1046/j.1365-2141.1999. 01146.x.

34-Högberg, C.; David, E.; Oscar, Ö. Mild hypothermia does not attenuate platelet aggregation and may even increase ADPstimulated platelet aggregation after clopidogrel treatment. Thrombosis J, 2009, 7, 2-7. DOI: 10.1186/1477-9560-7-2.

35-Born, G. Light on platelets. J Physiol, 2005, 568(3), 713-714. DOI: 10.1113/jphysiol.2005. 095778.

36-Xavier, R.; White, A.; Fox, S.; Wilcox, R.; Heptinstall, S. Enhanced platelet aggregation and activation under conditions of hypothermia. Thromb Haemost, 2007, 98,1266-75. DOI: 10.1160/TH07-03-0189.

37-Guillermo, G.; David, R.; Marian, E. Clinical review: Hemorrhagic shock. Critical Care, 2004, 8, 373-381. DOI: 10.1186/cc2851.

38-Klabunde, R. Cardiovascular integration and adaptation in cardiovascular physiology concepts. Lippincott Williams \& Wilkins, Chapter 9, 2005, PP 199-202. ISBN: 078175030X.

39-Dubin, A.; Estensoro, E.; Murias, G.; Canales, H.; Sottile, P.; Badie, J.; Barán, M.; Pálizas, F.; Laporte, M.; Rivas, D. Effects of hemorrhage on gastrointestinal oxygenation. Intensive Care Med, 2001, 27, 1931-1936. DOI: $10.1007 / \mathrm{s} 00134-001-1138-9$.

40-Erecinska, M.; Silver, I. Tissue oxygenation and brain sensitivity to hypoxia. Respir Physiol, 2001, 128, 263-276. DOI: 10.1016/S0034-5687 (01) 00306-1.

41-Ray, C.; Abbas, M.; Coney, A.; Marshall, J. Interactions of adenosine, prostaglandins and nitric oxide in hypoxia-induced vasodilatation: in vivo and in vitro studies. $J$ Physiol, 2002, 544, 195-209. DOI: 10.1113/jphysiol.2002.023440.

42-Timothy, S. Contributions of Inflammatory processes to the development of the early 
stages of diabetic retinopathy. Exp Diabetes Res, 2007, 95103. DOI: 10.1155/2007/95103.

43-Kowluru, R.; Odenbach, S. Role of interleukin$1 \beta$ in the pathogenesis of diabetic retinopathy. British J Ophthalmology, 2004, 88 (10), 1343-1347. DOI: 10. 1136/ bjo. 2003. 038133.

44-Baldwin, A. The Role of Inflammation in the Toxicity of Hemoglobin-Based Oxygen Carriers in Winslow, R. Blood Substitutes, Elsevier academic press, $2^{\text {nd }}$ ed., 2006; PP 235-242. ISBN: 13: 978-0-12-759760-7.

45-Fantidis, P.; Perez De Prada, T.; FernandezOrtiz, A.; Sanmartin, M.; Alfonso, F.; Hernandez, R.; Escaned, J.; Banuelos, C.; Sabate, M.; Macaya, C. Endogenous antiinflammatory response after coronary injury in a porcine model. European J Clinical Investigation, 2001, 31(12), 1019-1023. DOI: 10.1046/j.1365-2362.2001.00904.x.

46-Flaster, H.; Bernhagen, J.; Calandra, T.; Bucala, R. The macrophage migration inhibitory factor- glucocorticoid dyad: Regulation of inflammation and immunity. Molecular Endocrinology, 2007, 21(6), 1267-1280. DOI: $10.1186 /$ cc7970.

47-Okazawa, M.; Takao, K.; Hori, A.; Shiraki, T.; Matsumura, K.; Kobayashi, S. Ionic basis of cold receptors acting as thermostats. The Journal of Neuroscience, 2002, 22 (10), 3994-4001. PMID: 12019319.

48-Vinkers, C.; Lucianne, G.; Meg, J.; Koen, G.; Cor, J.; Ruud, O.; Ronald, S.; Berend, O.; Mechiel, K. Stress-induced hyperthermia and infection-induced fever: Two of a kind? Physiology and Behavior, 2009, 98,37-43. DOI: 10. 1016 / j. physbeh. 2009. 04. 004.

49-Hopkin, S. The pathophysiological role of cytokines. Legal Medicine, 2003, 5(1), S45S57. DOI:10.1016/S1344-6223(02)00088-3. 50-Marik, P. Fever in the ICU. Chest, 2000, 117: 855-869. DOI:10.1378/chest.117. 3.855.
51-Mackowiak P, Bartlett J And Borden E. Concepts of fever: Recent advances and lingering dogma. Clin Infect Dis, 1997, 25, 119-138. DOI: 10.1086/514520.

52-Cartmell, T.; Mitchell, D. The molecular basis of fever in: Handbook of stress and the brain. Steckler T.; Kalin N.; Reul J. (Eds.) Vol. 15. Chapter 2.4, Elsevier B.V, $2^{\text {nd }}$ ed., 2005. PP 193-230. ISBN: 0-444-51823-1.

53-Roth, J. Endogenous antipyretics. Clinica Chimica Acta, 2006, 371 (1-2), 13-24. DOI: 10.1016/j.cca.2006.02.013.

54-Mader, S. Understanding Human Anatomy and Physiology, The McGraw-Hill Companies, $5^{\text {th }}$ ed., 2004. PP 11-12. ISBN: 0072935170.

55-Martini, F.; Nath, J. Fundamentals of anatomy and physiology, Chapter 12, neural tissue, $8^{\text {th }}$ ed., 2009; PP 331-345. ISBN:13: 9780321505712.

56-Konrad, F.; Birgit, B.; Erland, E.; Robert, H. Sarcoplasmic reticulum $\mathrm{Ca}^{2+}$-ATPase modulates cardiac contraction and relaxation. Cardiovascular Research, 2003, 57 (1), 20-27. DOI: 10.1016/S00086363(02)00694-6.

57-Nahoul, K.; Daffos, F.; Forestier, F.; Scholler, R. Cortisol, cortisone and dehydroepiandrosterone sulfate levels in umbilical cord and maternal plasma between 21 and 30 weeks of pregnancy. Journal of Steroid Biochemistry, 1985, 23(4), 445-450. DOI:10.1016/0022-4731(85)90191-8.

58-Robles, L.; Ruggero, M. Mechanics of the Mammalian Cochlea. Physiological Reviews, 2001, 81 (3), 1305-1352. PMID: 11427697.

59-Stennicke, H.; Jurgensmeier, J.; Shin, H.; Deveraux, Q.; Wolf, B.; Yang, X.; Zhou, Q.; Ellerby, H.; Bredesen, D.; Green, D.; Reed, J.; Froelich, C.; Salvesen, G. Procaspase-3 is a major physiologic target of caspase-8. J. Biol. Chem, 1998, 273, 27084 27090. DOI: 10.1074/jbc.273.42.27084. 